\title{
DUAS PLACAS DE FERRO COM AS ARMAS DE MAURICIO DE NASSAU
}

\author{
WILLEM J. VAN BALEN \\ JOAQUIM DE SOUSA-LEÃO
}

Não há talvez período da nossa história que tenha despertado, da parte dos estudiosos, no Brasil e no exterior, maior interesse do que os trinta anos da aventura colonial da West-Indische-Compagnie no nordeste brasileiro.

A figura excelsa de Maurício de Nassau (1604-1679), soldado dos mais ilustres e cultos de seu tempo, cujo periodo de governo em Pernambuco (1637-1644) marcou o apogeu do Brasil holandês (1630-1654) é por demais conhecida e admirada para que seja necessário agora evocá-la.

O patrimônio artístico que nos legou "Maurício o Brasileiro", como é chamado na Holanda para diferenciá-lo do seu homônimo e padrinho o Príncipe de Orange (1589-1625), abrange, além dos in folio de Piso e Marcgrave, divulgando o conteúdo de suas coleções científicas que tanto contribuíram para a nossa cultura, os quadros do paisagista Frans Post e do naturalista Albert Eckhout, cujos óleos e aquarelas constituiam um dos tesouros da Biblioteca de Berlim, o Teatrum Rerum Naturalis Brasiliae (perdidos em conseqüência da Guerra) e a famosa Tenture des Indes que celebra o cenário transatlântico de suas conquistas, revivido após três séculos numa memorável exposição em 1953 (reencenada no Museu de Arte Moderna do Rio de Janeiro em 1968, sob os auspícios dos governos holandês e brasileiro), a qual teve lugar na Mauritshuis, aquele palácio que em Haia recorda a memória do Mecenas que a construiu, o mais belo monumento no gênero da Renascença holandesa. Inspirada no classicismo de Serlio e Palladio, os festōes e guirlandas que decoram suas cimalhas e lareiras, talhadas nas espécies mais finas da nossa selva, obedecem ao risco do famoso arquiteto Pieter Post. Infelizmente estas desapareceram num incêndio de 1704, que destruiu também o interior dessa jóia 
arquitetônica, inclusive as belas chaminés néo-clássicas do piso nobre como as menores dos quartos e salas de que a Biblioteca Real guarda as plantas e desenhos.

O aparecimento recente de duas placas de ferro no mercado de arte holandês, ostentando o brasão de armas de João Maurício de Nassau-Siegen, formam os elos de uma cadeia que nos liga à grande figura da história comum dos dois paises e quiçá ao mais belo ornamento arquitetural da capital da Holanda.

Abrem-se assim novas perspectivas para a biografia do herói e para a reconstituição do palácio.

Dado seu interesse histórico, uma dessas peças foi logo adquirida pelo Rijksmuseum de Amsterdam (n. ${ }^{\circ}$ NG 541 do respectivo inventário). Ela conserva o seu aspecto original e provém de uma granja perto de Doetinchem (Condado de Zutphen), onde era usada como placa de lareira. O outro exem-

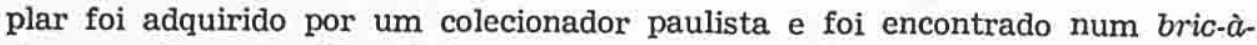
-brac em Deventer (Provincia de Overijsel). Este é pintado e envernizado nas cores que correspondem às do brasão dos Nassau o mesmo que figura, igualmente à cores, no frontão da Mauritshuis. Descrevamos a peça heráldica. Esquartelado: o primeiro representa Nassau (tradução literal: várzea úmida), um modesto burgo no rio Lahn, mas que deu uma dinastia ilustre de reis e imperadores; o segundo mostra o leão de Katzenelbogen e no terceiro aparecem os dois leopardos de Dietz, acastelados burgos medievais; o quarto representa Vianden, no Luxemburgo (Países Baixos, portanto o Bonelux de hoje) sobre o rio Our, que por via do Mosela e do Reno, deságua no Mar do Norte em Hoek van Holland.

Nessas placas, o brasão está sobreposto à Cruz de Malta por ter Mauricio de Nassau assumido em 1652 o grão mestrado da Ordem Johannita, em Sonnemburg (Alemanha Oriental) e, aparece enlaçado pela banda do Elefante Branco, com que o distinguiu o Rei da Dinamarca, emblemas de duas insignes ordens de cavalaria. Na mesma data fora João Maurício elevado à categoria de Príncipe do Sacro-Império-Alemão.

Acrescido desses atributos, compôs-lhe o escudo Maurício Post, seu arquiteto em Siegen e Cleves, onde o Príncipe exercia a loco-tenência do Eleitor de Brandeburgo em suas enclaves renanas. E ele filho do famoso arquiteto dos Oranges, Pieter Post, sobrinho portanto de Frans e afilhado de Joāo Maurício de Nassau.

Lê-se abaixo a inscrição: "Joh. Mau. Nas. Prin." (Johannes Maurits Nassaviae Princeps).

A julgar pelas charneiras que as placas apresentam nas duas arestas laterais opostas, parece que elas formam a parte inferior de um portão de ferro para uma grade de jardim, qual o que o cercava na época a Mauritshuis. 


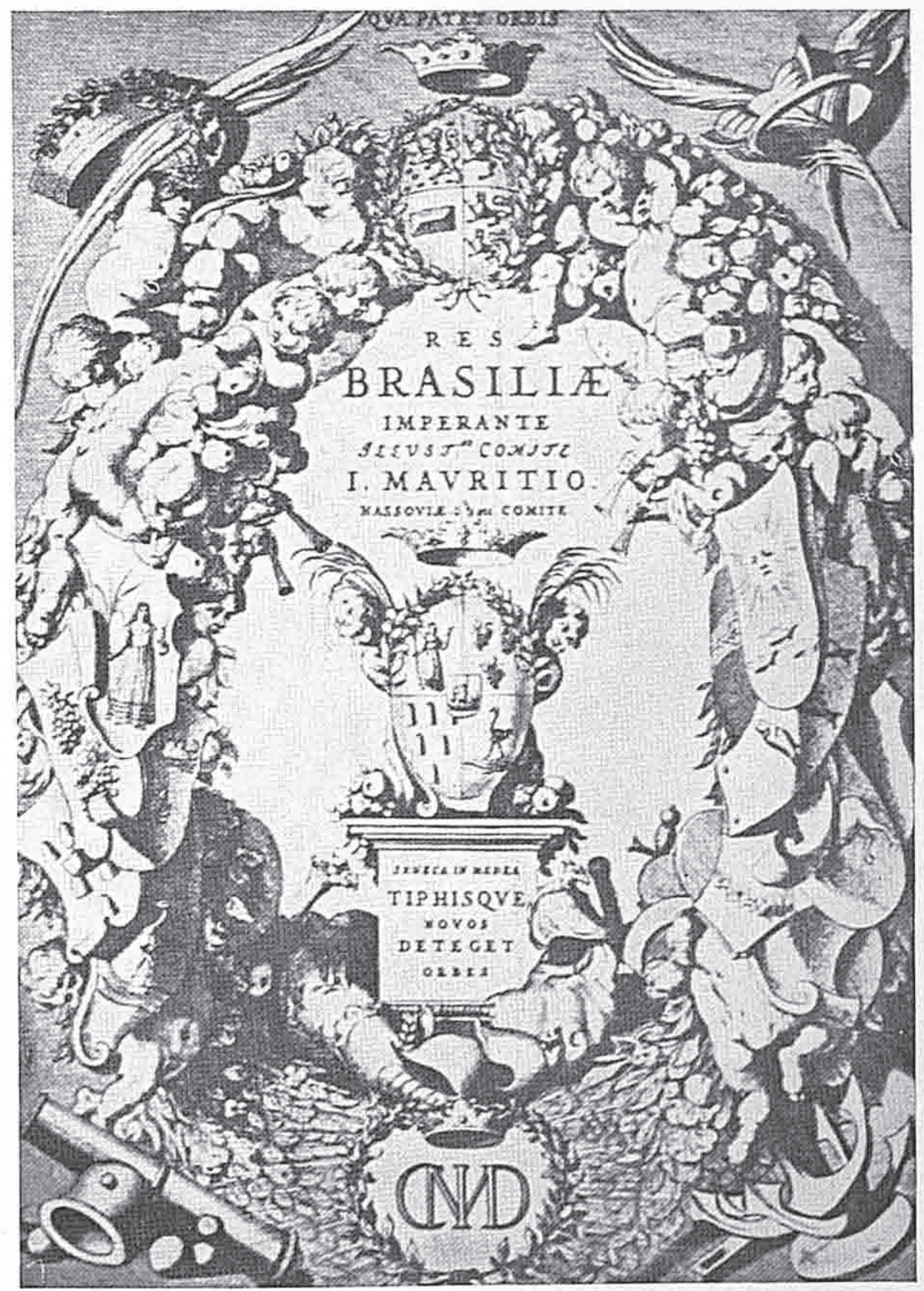

Frontispicio do livro de Casperus Barlaeus sobre os oito anos de governo, no Brasil holandês, do Conde João Mauricio de Nassau. Amsterdam 1647. 


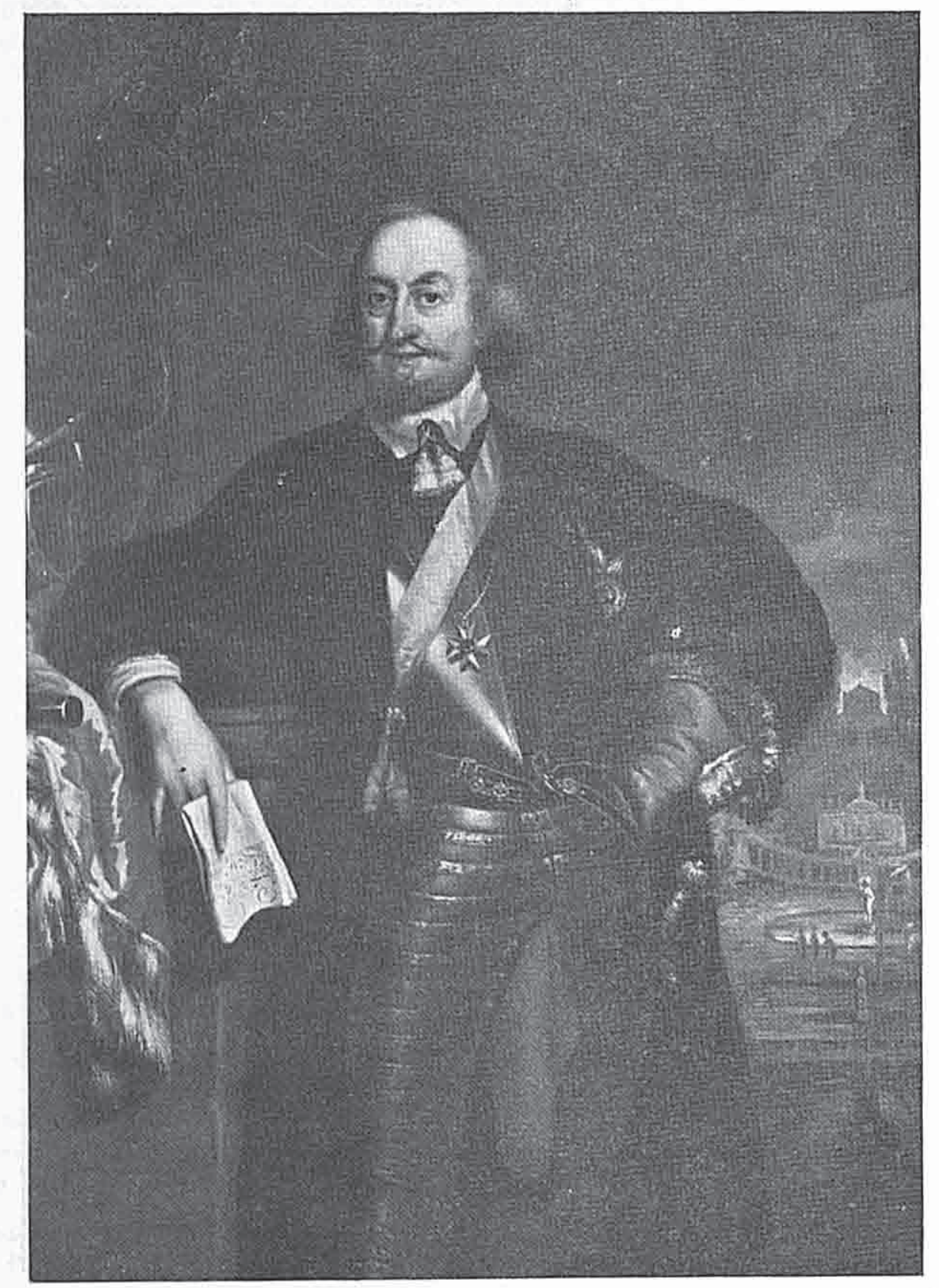

JEAN DE BAEN, Retrato de João Mauricio de Nassau. Mauritshuis, Haia. 

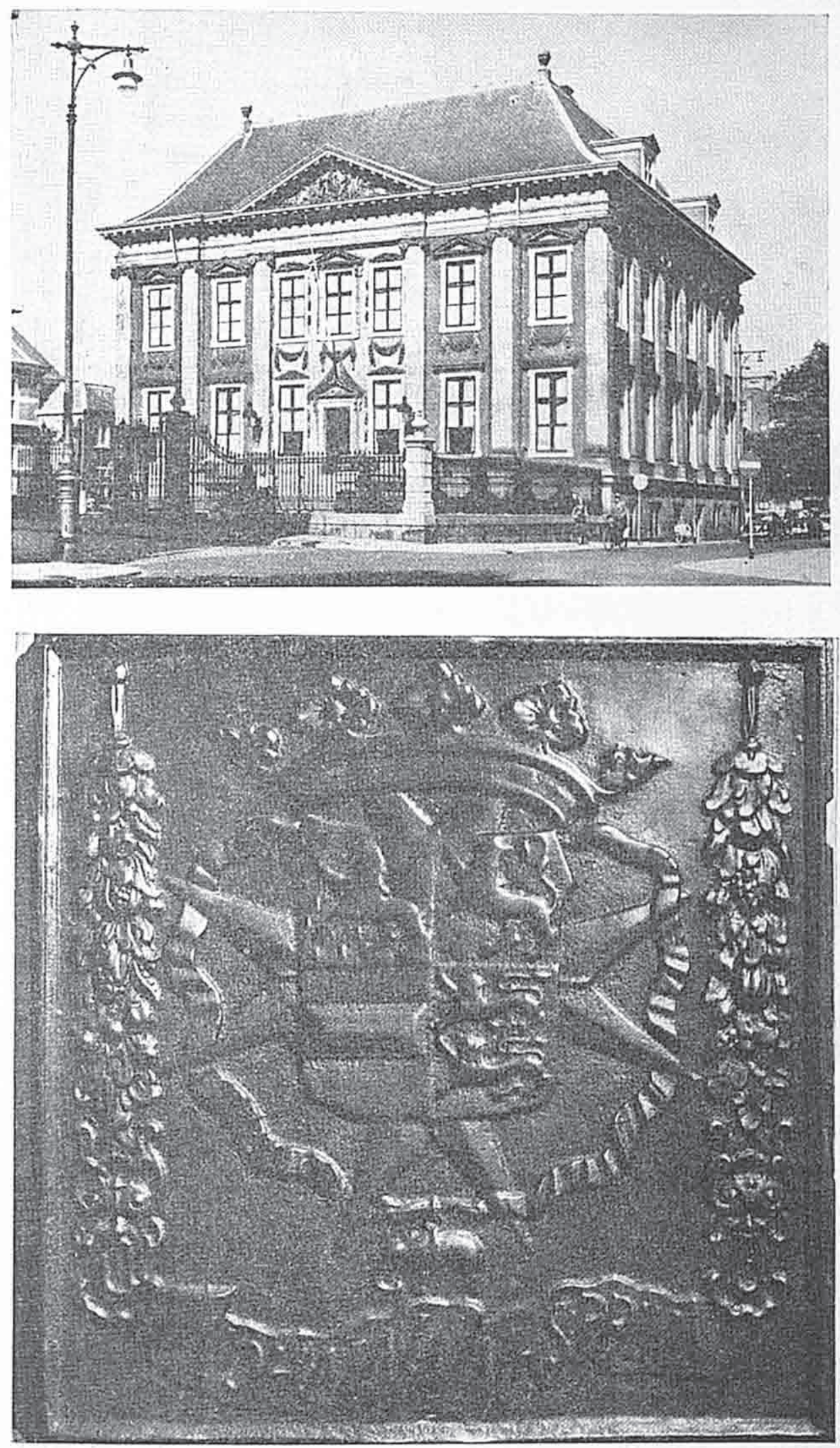

1. Mauritshuis (residência de Joäo Mauricio de Nassau) Haia.

2. Placa com as armas de João Maurício de Nassau, em ferro $76,5 \times 77,5 \mathrm{~cm}$. Rijksmuseu, Amsterdam. 


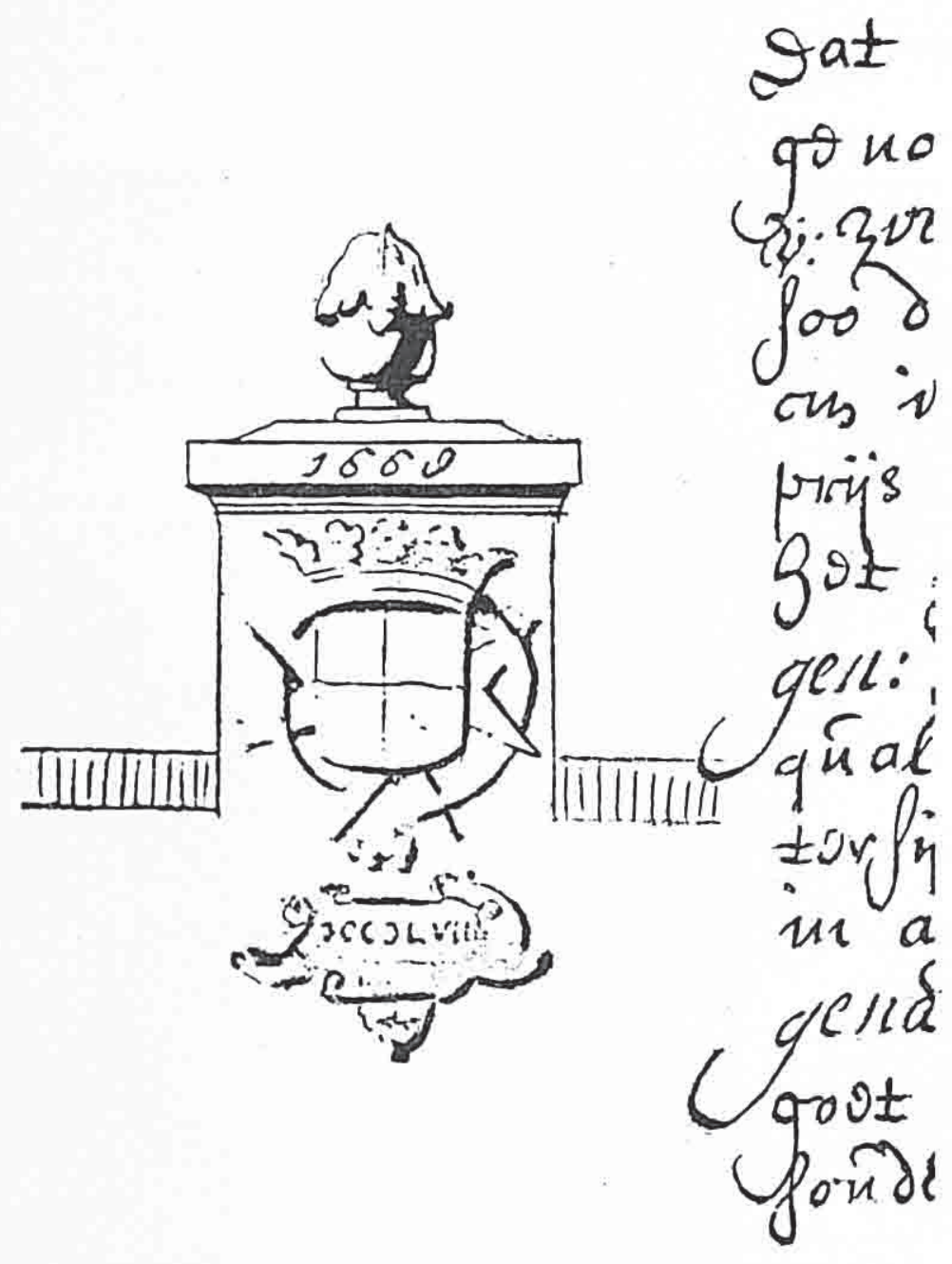

Teekening van Maurits Post

voor het op de kade aan te brengen wapen.

Terzijde van den brief van 7 Sepiembar 1668

Desenho do Brasão por Maurits Post (de uma carta datada de 7 de setembro de 1668 ). 


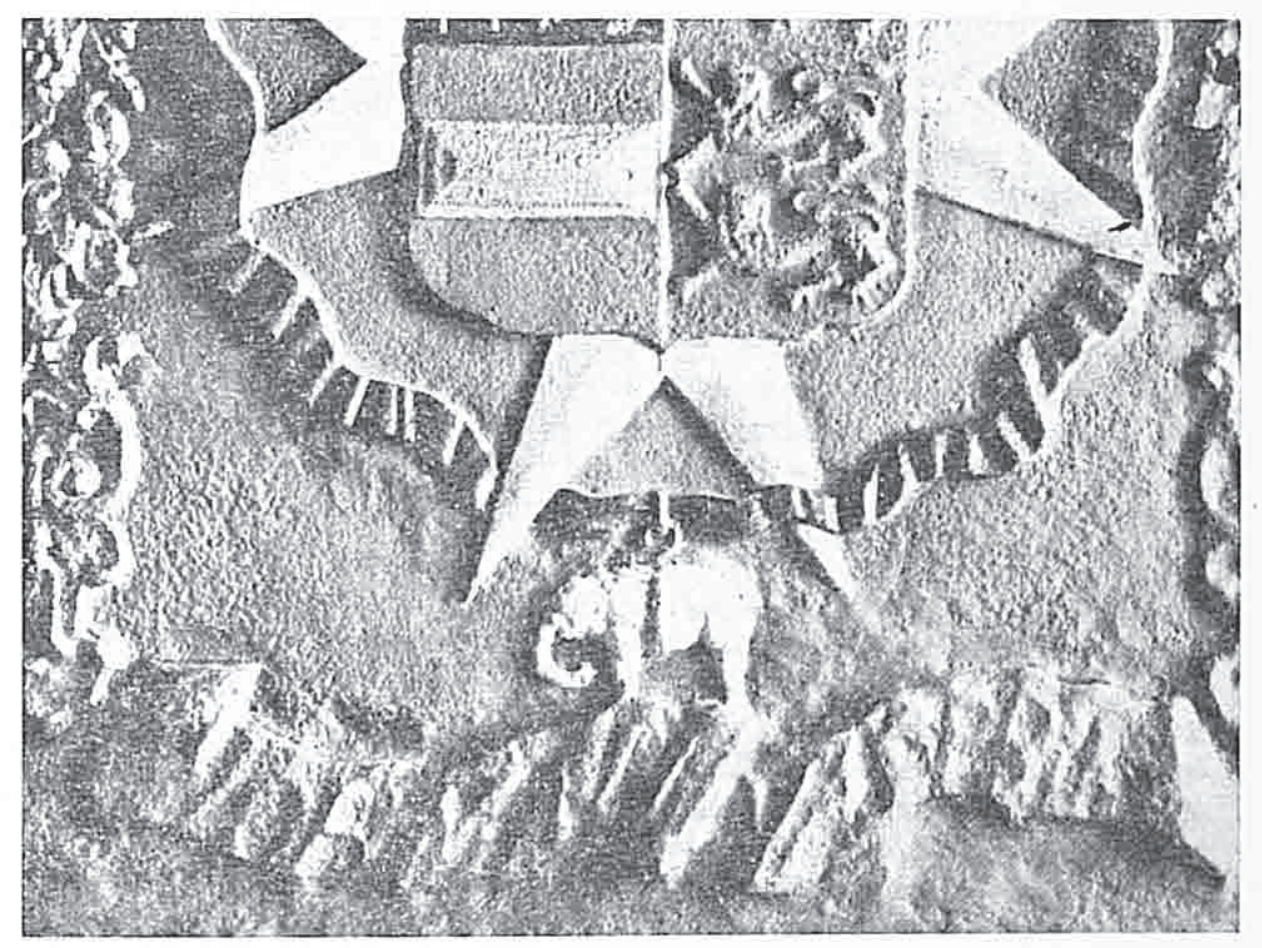

Idem. Detalhe. 
Conhecemos a referida composição do desenho incluso que orna uma pilastra para o mesmo jardim, manuscrito de autoria de Mauricio Post publicada na revista haguense Jaarboek de 1940.

Desconhece-se o lugar da fabricação dessas placas. Terão saído de alguma das construçōes erigidas por Maurício de Nassau em Haia, Sonnenburg, Cleve ou Siegen? Ou terão servido de marca pessoal, quais os retratos com que o Príncipe, propenso à grandeza, mas não brindado pela fortuna, costumava honrar seus amigos e colaboradores mais dedicados? Neste caso, é possivel que existam outros exemplares da mesma fundição na Holanda e fora dela.

Para concluir, lembremos que na prolifica linhagem dos Nassau não faltam ramificaçōes: Nassau-Dillenburg, em cujo castelo nasceram o grande Taciturno e, em 1604, João Maurício, afilhado de Maurício de Orange-Nassau, Stadhouder das Províncias Unidas; Nassau-Siegen, em cujo castelo de baixo ("in hinteren Schloss") está sepultado João Maurício; Nassau Beilstein e Hadamar, territórios atravessados pelo Lahn e Sieg, afluentes do Reno. O condado de Nassau está no país dos Hessen (lat. Chatti), tribo selvagem e belicosa que expulsou os bátavos, mais dóceis, indo estes fixar-se no delta renano (a Holanda de hoje). Mercadores de Hessen costumavam atravessar os Paises Baixos com suas caravanas carregadas de mercadorias com as quais comerciavam nos portos do Norte. Esses caminhos guardam o nome de "Hessenwegen".

Também os Nassau, na Idade Média, tomaram pé nos ditos Países Baixos, conhecidos pela sua prosperidade baseada no queijo, na lã e no arenque. Um ramo estabeleceu-se em Diest (Brabante belga), onde está sepultado o primogênito do Taciturno, Dom Filipe Guilherme, o Orange espanhol, por ter ele sido raptado por Filipe II, como refém contra o pai revoltado, chefe da insurreição neerlandesa. Outro ramo fixou-se em Breda (Brabante holandês), cortada em duas partes pela fronteira belgo-bátava: Baerle-Hertog (do duque de Brabante) e Baerle-Nassau (da baronia de Breda), domínio de Engelbert de Nassau na Idade Média, cujo túmulo constitui um dos monumentos da venerável cidade. 